Neuroepidemiology 2012;39:143-144

DOI: $\underline{10.1159 / 000341535}$

\section{Circulating Urine Phthalates Are not Associated with a Decline in Cognition in Adults and the Elderly: NHANES, 1999-2002}

\author{
Ivy Shiue ${ }^{\mathrm{a}, \mathrm{b}}$, John Starr ${ }^{\mathrm{a}}$ \\ ${ }^{a}$ Centre of Cognitive Ageing and Cognitive Epidemiology, \\ University of Edinburgh, Edinburgh, UK; ${ }^{\mathrm{b}}$ The William A. \& \\ Barbara R. Owens Institute for Behavioral Research, University \\ of Georgia, Athens, Ga., USA
}

Some chemical pollutants may act as hormone mimics and thus affect the central nervous system [1]. A number of environmental pollutants have been shown to disrupt endocrine function in animals, leading to long-lasting cognitive deficits in primates [2], and are likely to reprogramme (neuro)physiological set-points and to increase susceptibility to disease later in life [3]. Phthalates, a chemical estrogen widely used in the food-packaging industry [4], leach from the polymers into food and water under normal conditions and can be detected in human urine. Animal studies have shown that chronic exposure to these, even at low doses, can alter some biological end points $[5,6]$. A study in children suggests that some phthalates are detrimental to cognition development [7]. However, the effects on adults are undetermined. In this context, we aimed to study the associations of urine phthalate concentrations and cognitive function in adults $\geq 60$ years old.

\section{Methods}

As described elsewhere [8], the US National Health and Nutrition Examination Surveys is a population-based multi-year crosssectional study. Assessments on both urine phthalate concentrations and cognitive function were only available between 1999 and 2002. Information on demographics and cognitive function (using Digit Symbol Substitution test, DSS; range 0-133) [9] was obtained by household interview and people were selected (still representative) from whom urine was collected in order to measure phthalate volumes (using online solid-phase extraction, isotope dilution and high-performance liquid chromatography separation, followed by electrospray ionization and tandem mass spectrometry) [10].
The effects of circulating phthalates on cognitive function were examined by a Student $t$ test and a generalized linear model, with $\mathrm{p}<0.05$ considered statistically significant. We adjusted first for age, sex and urine creatinine (model A) and then also for education (model B). STATA statistical software version 12.0 (STATA, College Station, Tex., USA) was used to perform all the analyses.

Results

Cognitive data was available on 1,834 subjects for the period 1999-2000 and on 1,872 for 2001-2002. After combining these with the available data on urine phthalate concentrations, the analytic sample was 462 subjects for 2001-2002 and 412 for 19992000. The mean DSS scores for these 2 cohorts were $42.19 \pm 18.20$ (range $0-100$ ) and $39.27 \pm 19.15$ (range $0-117$ ), respectively. Table 1 presents the association of each urine phthalate concentration and DSS score. There were no clear associations between urine phthalate concentrations and DSS scores after full adjustments, although a high mono-benzyl phthalate concentration was shown once to be significantly associated with a low DSS score in the crude model (Beta $-0.088 ; 95 \% \mathrm{CI}-0.158$ to $-0.018 ; \mathrm{p}=0.014$ ) and in model A (Beta $-0.097 ; 95 \%$ CI -0.174 to $-0.019 ; \mathrm{p}=0.014$ ) before education was adjusted in model $\mathrm{B}$ as well. The other two positive effects also disappeared after full adjustments.

\section{Discussion}

In this study, we found no evidence that urine phthalates are associated with cognitive impairment in adults over 60 years of age. A strength of this study is that it comprises a large sample from a national setting. A weakness is that only one cognitive function test was administered: future research is required to test other cognitive domains such as episodic memory. Future studies could also include other environmental chemicals that might potentially disrupt endogenous estrogen, androgen and thyroid function and so influence brain plasticity.

Acknowledgements

I.S. has a scholarship from the Centre of Cognitive Ageing and Cognitive Epidemiology at the University of Edinburgh.

\section{KARGER \\ Fax +41613061234 E-Mail karger@karger.ch} www.karger.com
(C) 2012 S. Karger AG, Base

$0251-5350 / 12 / 0392-0143 \$ 38.00 / 0$

Accessible online at:

www.karger.com/ned
Prof. John Starr

Centre of Cognitive Ageing and Cognitive Epidemiology

Department of Psychology, University of Edinburgh

7 George Square, Edinburgh EH8 9JZ (UK)

Tel. +44 131650 4340, E-Mail jstarr@staffmail.ed.ac.uk 


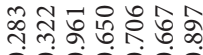

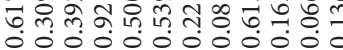
จे

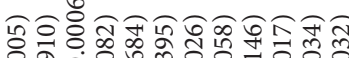

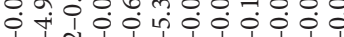

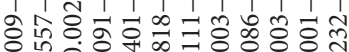

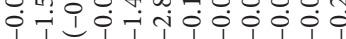

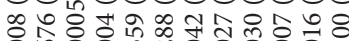
它

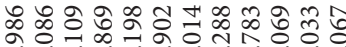

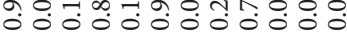

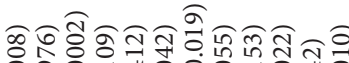

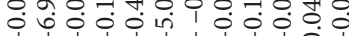

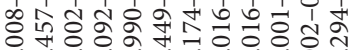
0.0.0. 눙

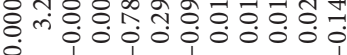

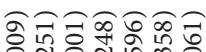

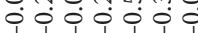

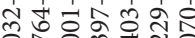

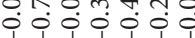

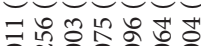
1
0
0
0

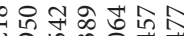

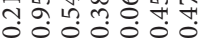
ลํํำิำณ 00070.000

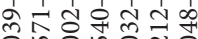

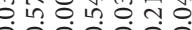
ilipili

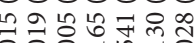
i.

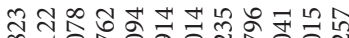

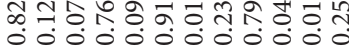

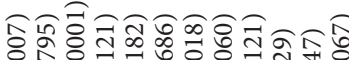
0.

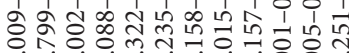
0.0.0. m in

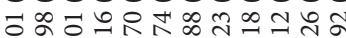

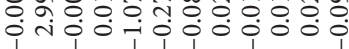

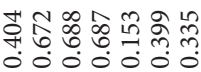

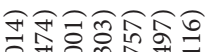

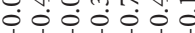

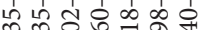

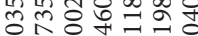
i i i i i i i i

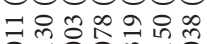

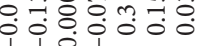
\% จำ

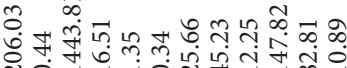
$+1+1+1+1+1+1+1+1+1+1+1$ 大ิฟ

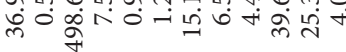

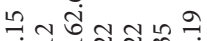

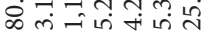
$+1+1+1+1+1+1+1$

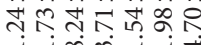

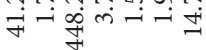

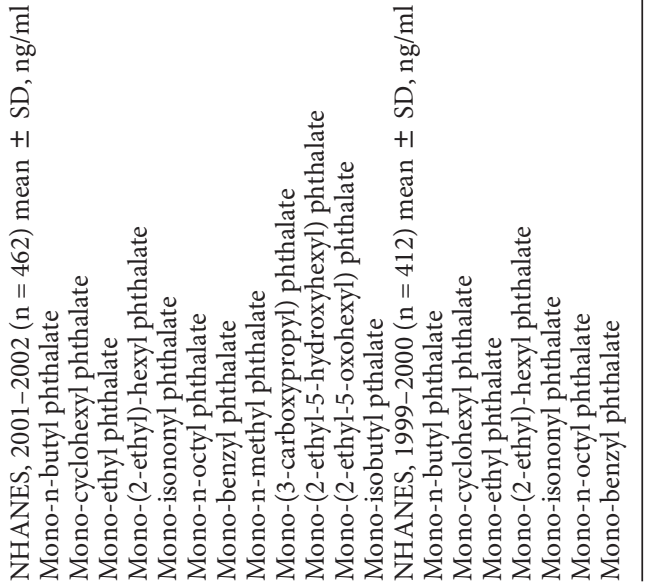

\section{References}

1 Schantz SL, Widholm JJ: Cognitive effects of endocrine-disrupting chemicals in animals. Environ Health Prospect. 2001;109:1197-1206.

$\checkmark 2$ Paule MG, Li M, Allen RR, Liu F, Zou X, Hotchkiss C, Hanig JP, Patterson TA, Slikker W Jr, Wang C: Ketamine anesthesia during the first week of life can cause long-lasting cognitive deficits in rhesus monkeys. Neurotoxico Teratol 2011;33:220-230.

3 Fox DA, Grandjean P, de Groot D, Paule MG: Developmental origins of adult disease and neurotoxicity: epidemiological and experienmental studies. Neurotoxicology 2012, E-pub ahead of print.

-4 Brotons JA, Olea-Serrano MF, Villalobos M, Pedraza V, Olea N: Xenoestrogens released from lacquer coatings in food cans. Environ Health Perspect 1995;103:608-612.

5 Bisset KM, Dhopeshwarkar AS, Liao C, Nicholson RA: The G proteincoupled cannabinoid-1 (CB1) receptor of mammalian brain: inhibition by phthalate esters in vitro. Neurochem Int 2011;59:706-713.

-6 Boas M, Main KM, Feldt-Rasmussen U: Environmental chemicals and thyroid function: an update. Curr Opin Endocrinol Diabetes Obes 2009;16:385-389.

$\checkmark 7$ Kim BN, Cho SC, Kim Y, Shin MS, Yoo HJ, Kim JW, Yang YH, Kim HW, Bhang SY, Hong YC: Phthalates exposure and attention-deficit/ hyperactivity disorder in school-age children. Biological Psychiatry 2009;66:958-963.

8 Centers for Disease Control and Prevention (CDC): National Center for Health Statistics (NCHS). National Health and Nutrition Examination Survey Data. Hyattsville, US Department of Health and Human Services, 2012. http://www.cdc.gov/nchs/nhanes.htm

9 WAIS-III WMS-III Technical Manual. San Antonio, The Psychological Corporation, Harcourt Brace and Company, 1997.

10 Silva MJ, Barr DB, Reidy JA, Malek NA, Hodge CC, Caudill SP, Brock JW, Needham LL, Calafat AM: Urinary levels of seven phthalate metabolites in the U.S. population from the National Health and Nutrition Examination Survey (NHANES) 1999-2000. Environ Health Perspect 2004;112:331-338. 